\title{
Reabilitação estética do sorriso por meio de reanatomização dentária: Relato de caso
}

\author{
Esthetic resolution of smile through dental reanatomization: Case report \\ Rehabilitación estética de la sonrisa mediante reanatomización dental: Reporte de caso
}

Recebido: 22/12/2020 | Revisado: 24/12/2020 | Aceito: 30/12/2020 | Publicado: 03/01/2021

\author{
Andrey Gonçalves Emídio \\ ORCID: https://orcid.org/0000-0002-8597-1505 \\ Universidade de São Paulo, Brasil \\ E-mail: andrey.goncalves130@gmail.com \\ Sergio Kiyoshi Ishikiriama \\ ORCID: https://orcid.org/0000-0003-0064-1783 \\ Universidade de São Paulo, Brasil \\ E-mail: serginho@usp.br
}

\begin{abstract}
Resumo
Os padrões de beleza estabelecidos pela sociedade vêm sendo um fator decisivo para o aumento de pacientes à procura da odontologia estética a fim de obterem um sorriso harmonioso. Dentro desse contexto, as queixas mais frequentes acerca do tratamento odontológico que visa melhorar a aparência do sorriso são as alterações de cor, forma e tamanho dos dentes. Objetivou-se com esse trabalho relatar um caso de resolução estética em que a paciente se queixava de múltiplos diastemas após o tratamento ortodôntico. Utilizou-se a reanatomização dos elementos 13 ao 23 pela técnica direta em resina composta com o auxílio da guia palatina. Os resultados obtidos evidenciaram que a técnica embasada em planejamento prévio acurado é capaz de resolver casos estéticos com rapidez, segurança e previsibilidade. Assim sendo, concluiu-se que as resinas compostas permitem a reabilitação estética do sorriso de forma direta, com um bom custo-benefício e resultados estéticos excelentes. Ademais, observou-se que a reanatomização dentária com o objetivo de finalização pós-ortodôntica pode ser necessária em casos que requerem mudanças em proporções dentárias.
\end{abstract}

Palavras-chave: Resinas compostas; Dentística operatória; Estética.

\begin{abstract}
The beauty standards established by society have been a determining factor in the increase of patients looking for cosmetic dentistry in order to obtain a symmetrical smile. Within this context, the most wanted dental treatments to improve the smiles appearance are the ones used to change the teeth color, shape, and size. This paper aims to report a case of an esthetic solution in which the patient complained about multiple diastemas after making an orthodontic treatment. The treatment chosen was the dental reanatomization of the elements 13 to 23 by the direct technique in composite resin with the help of palatal silicon index. The obtained results showed that the technique based on accurate prior planning is capable of solving esthetic cases quickly, safely, and predictably. Therefore, it was also possible to conclude that the composite resins allow the esthetic rehabilitation of the smile in a direct way, with a good cost-benefit and excellent results. In addition, it was observed that dental reanatomization may be necessary for the purpose of post orthodontic treatment in cases that require changes in dental proportions.
\end{abstract}

Keywords: Composite resins; Dentistry operative; Esthetics.

\begin{abstract}
Resumen
Los estándares de belleza establecidos por la sociedad han sido un factor decisivo en el aumento de pacientes que buscan la odontología cosmética para obtener una sonrisa armoniosa. En este contexto, las quejas más frecuentes sobre los tratamientos odontológicos destinados a mejorar la apariencia de la sonrisa son los cambios en el color, la forma y el tamaño de los dientes. El objetivo de este estudio fue reportar un caso de resolución estética en el que el paciente se quejó de múltiples diastemas después de un tratamiento de ortodoncia. Se utilizó la reanimación de los elementos 13 a 23 mediante la técnica directa en resina compuesta con la ayuda de la guía palatina. Los resultados obtenidos mostraron que la técnica basada en una planificación previa precisa es capaz de resolver casos estéticos de forma rápida, segura y predecible. Por tanto, se concluyó que las resinas compuestas permiten la rehabilitación estética de la sonrisa de forma directa, con un buen coste-beneficio y excelentes resultados estéticos. Además, se observó que la reanimación dental con el objetivo de completar la ortodoncia puede ser necesaria en casos que requieran cambios en las proporciones dentales.
\end{abstract}

Palabras clave: Resinas compuestas; Odontología operatória; Estética. 


\section{Introdução}

A mídia tem supervalorizado determinados padrões de beleza, levando as pessoas a desejarem um sorriso e um corpo considerados "ideais". Em consequência disso, a busca pela perfeição das formas e dimensões dentárias aumentou exponencialmente, atraindo cada vez mais pacientes para as áreas que envolvem a Odontologia Estética, a qual possui variados recursos para tornar o sorriso mais belo e reestabelecer a harmonia facial (Gil, 2001; Rufenacht, 1998).

Esse aumento pela procura de procedimentos estéticos odontológicos evidencia aos profissionais a importância de obter um conhecimento acurado sobre a estética facial, a morfologia dentária, os detalhes anatômicos de dentes anteriores e quais as técnicas restauradoras disponíveis. Assim, o cirurgião-dentista precisa desenvolver suas habilidades a fim de proporcionar resultados satisfatórios aos pacientes que o buscam (Higileh, 2017; Moraes, Moreira Junior, Peralta, Scherma \& Resende, 2013).

Entre as queixas mais frequentes quanto ao sorriso, estão as alterações de cor, forma e tamanho dos dentes. Nesse âmbito, a presença de diastemas é um fator que gera inúmeras dúvidas no que se refere à abordagem clínica entre odontopediatras, ortodontistas, especialistas em dentística, periodontistas e até mesmo clínicos gerais. A presença de espaços interdentários desfavorece a beleza e a harmonia do sorriso e do conjunto dentofacial e pode prejudicar o bem-estar e as relações sociais dos indivíduos (Bandéca, 2011; D'altoé, Benedet, 2007, citado em Follak et al., 2012).

Dentro desse contexto, a descoberta do condicionamento ácido associado ao uso de sistemas adesivos elevou a Odontologia Restauradora a um novo patamar, permitindo a reconstrução e a simulação de estruturas dentárias por meio de técnicas minimamente invasivas. Desse modo, o sucesso clínico se deu a partir da interação de dois materiais já devidamente conceituados na literatura: a porcelana e a resina composta (Sene, Kasuya, 2016).

O progresso dos sistemas adesivos ofereceu um enriquecimento da união biomecânica entre dente e restauração, admitindo uma abordagem mais conservadora. Embora opções diretas e indiretas estejam disponíveis como tratamento restaurador, cuidados quanto à retirada de estrutura dentária saudável, número de sessões e durabilidade da restauração devem ser avaliadas durante o planejamento restaurador (Prieto et al., 2014; Santos-Pinto, Nagle \& Ricci, 2014 citado em Gouveia, Moreira Junior, Peralta, Scherma \& Resende, 2018).

Nesse sentido, as restaurações diretas utilizando resina composta resultam em procedimentos de mínima intervenção em comparação às restaurações indiretas. Isso porque podem ser facilmente reparadas em boca e possuem menor custo, o que as torna uma alternativa mais conservadora para os pacientes que necessitam de procedimentos restauradores em dentes anteriores (Baratieri, Ritter \& Andrada, 1994; Sameni, 2013).

É indispensável, entretanto, que, em todos os casos de reanatomização dentária, seja realizado um correto planejamento clínico a fim de que as pretensões de cada paciente sejam respeitadas durante o tratamento e possa-se obter um resultado que agrade tanto o cirurgião dentista quanto seu paciente (Renato Almeida, R., Garib, Henriques, Almeida, M. \& Renata Almeida, 1999).

Assim, tendo em vista as questões supramencionadas, o presente trabalho objetivou relatar um caso de reanatomização em resina composta em que a paciente se queixava de múltiplos diastemas após ter realizado o tratamento ortodôntico. Com o intuito de reverter esse quadro, optou-se pela técnica direta em resina composta para recuperação da harmonia do sorriso e autoestima da paciente.

\section{Relato de Caso}

A paciente V.N.L., 18 anos, gênero feminino, leucoderma, buscou tratamento odontológico na Clínica de Dentística da FOB-USP queixando-se de múltiplos diastemas após finalizar seu tratamento ortodôntico (Figura 1, 2, 3 e 4). 
Research, Society and Development, v. 10, n. 1, e7810111428, 2021

(CC BY 4.0) | ISSN 2525-3409 | DOI: http://dx.doi.org/10.33448/rsd-v10i1.11428

Figura 1. Vista frontal do rosto da paciente.

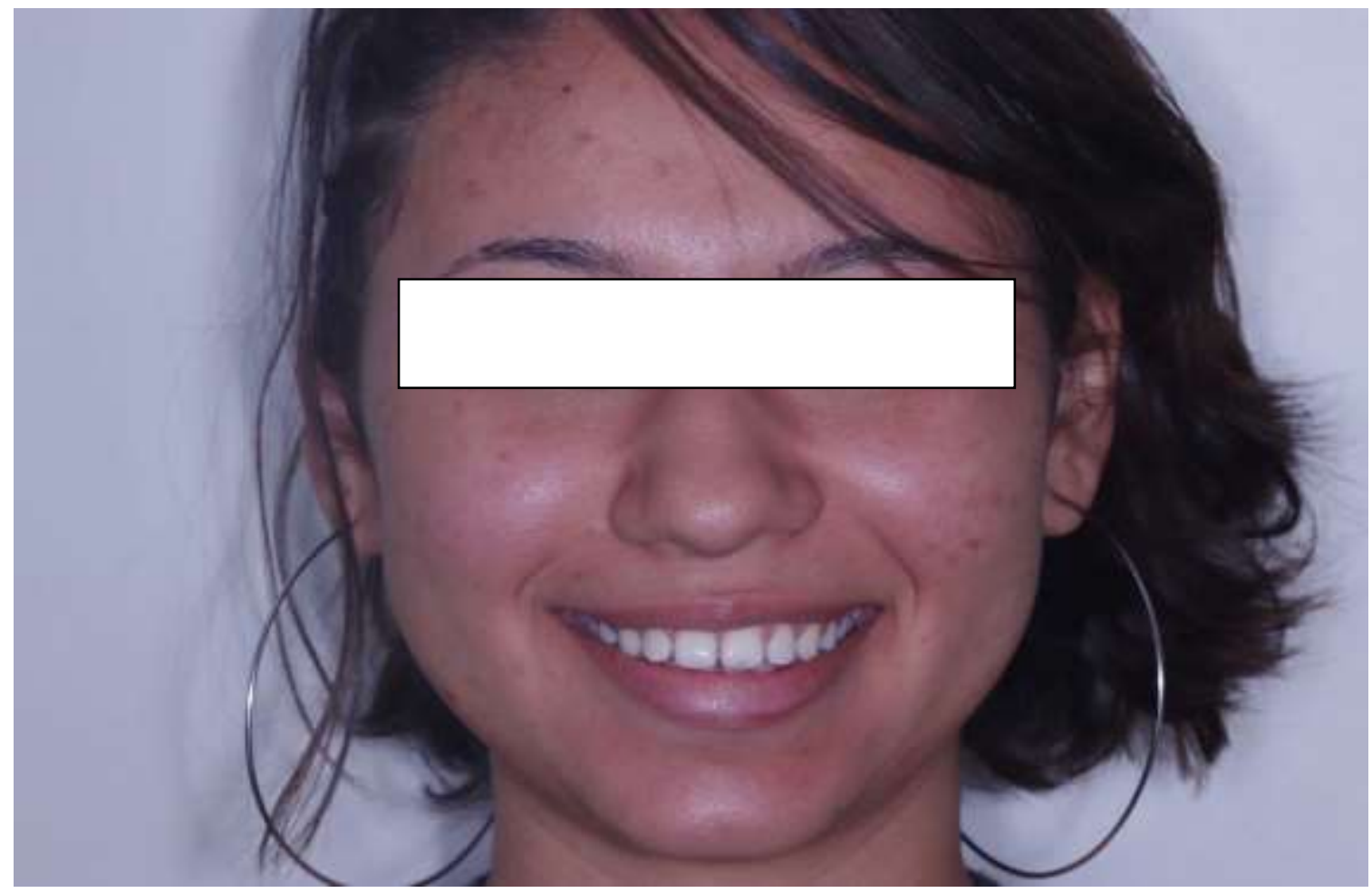

Fonte: Autores.

Figura 2. Vista extrabucal frontal do sorriso.

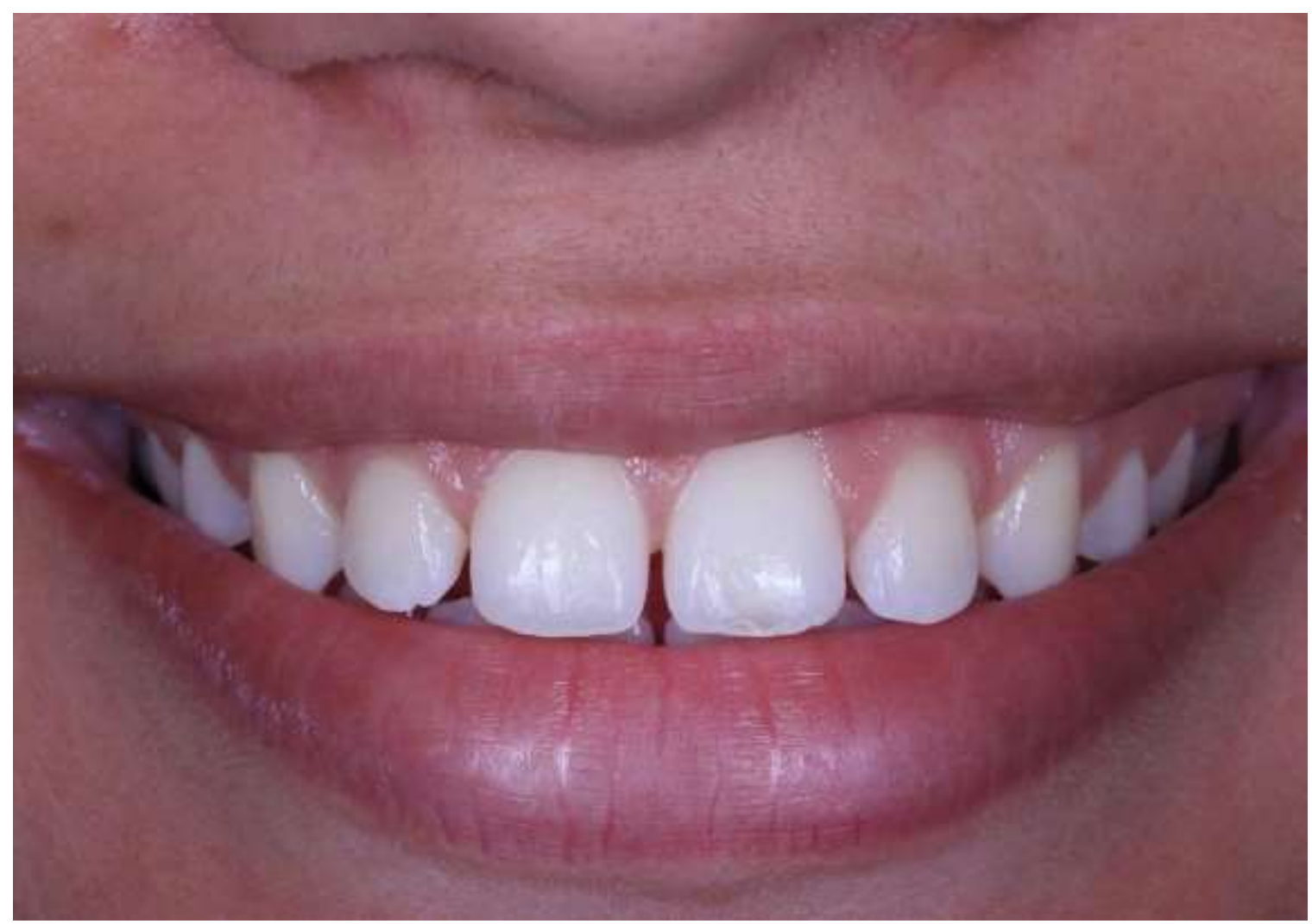

Fonte: Autores. 
Figura 3. Vista intrabucal dos dentes em oclusão.

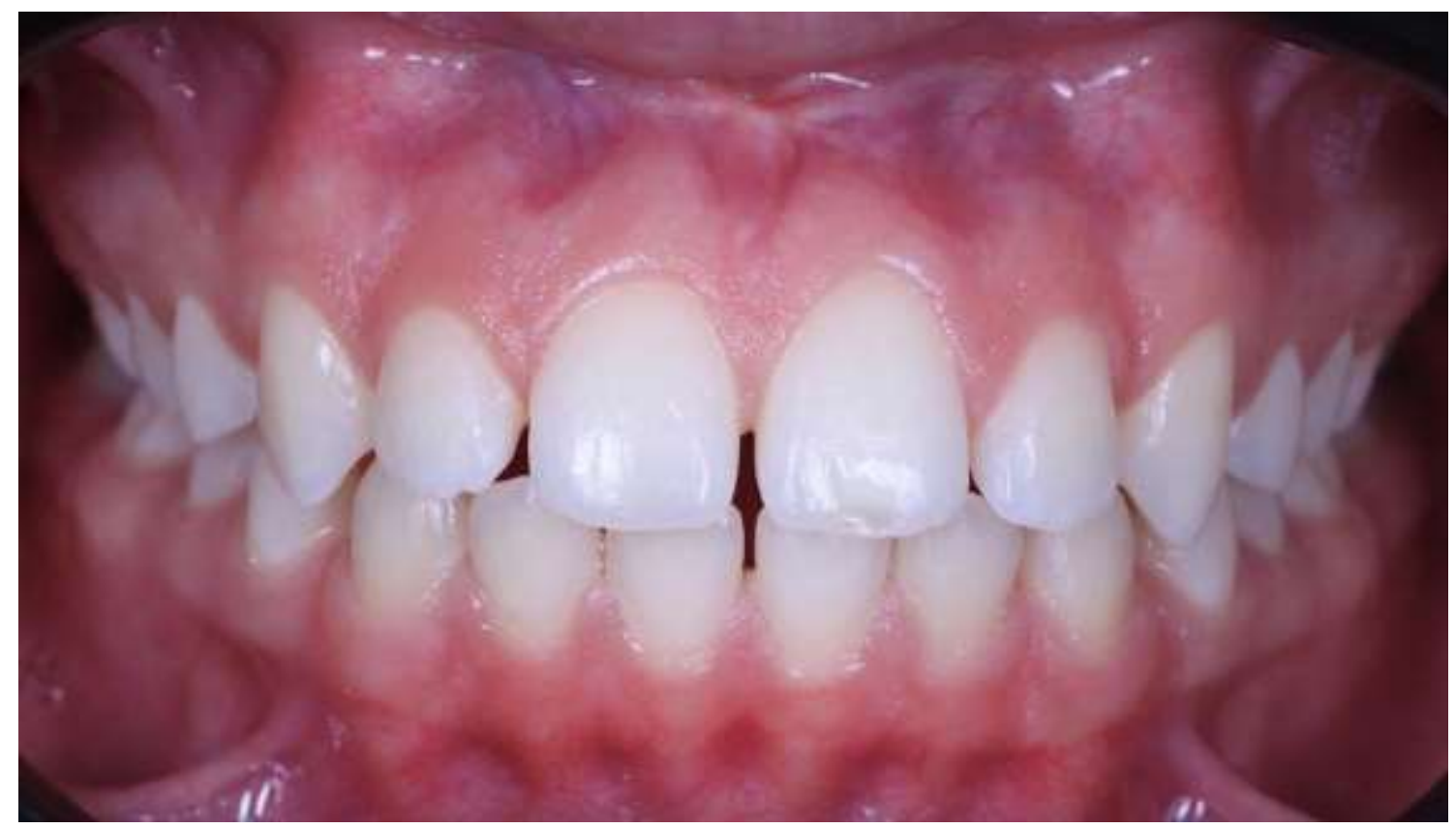

Fonte: Autores.

Figura 4. Arcada superior com fundo escuro.

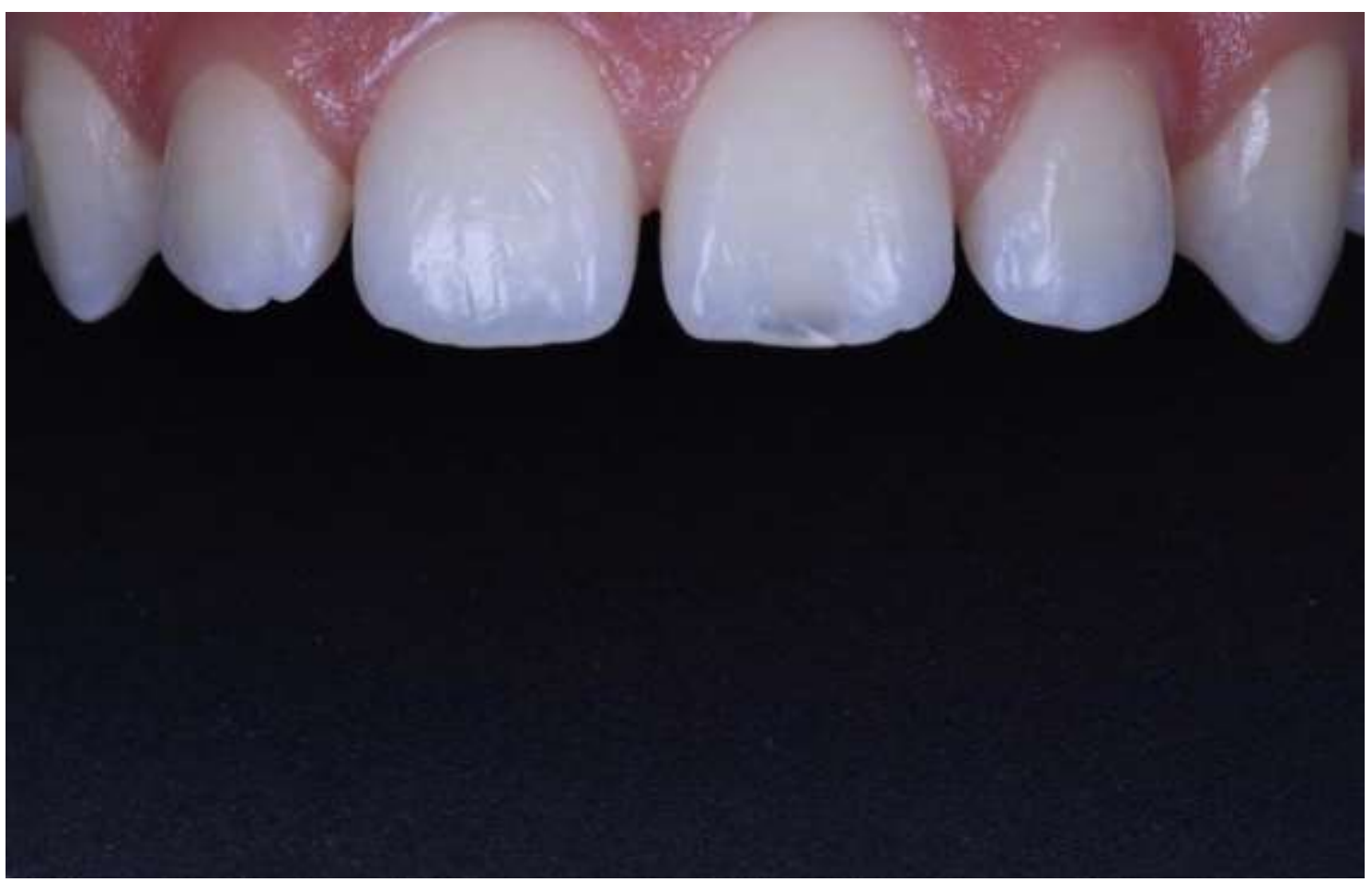

Fonte: Autores.

Após anamnese e exame clínico, decidiu-se que seria realizada a reanatomização dos elementos 13 ao 23 pela técnica direta em resina composta com o auxílio da guia palatina. Primeiramente, foram selecionadas as cores com auxílio da escala de cor VITA (Vitapan Classical, Wilcos, Alemanha), e, posteriormente, foi feita a moldagem para enceramento diagnóstico (Figura 5), o qual tem por intuito simular e planejar o tamanho e a forma dos dentes após a restauração. 
Figura 5. Modelo de gesso com enceramento diagnóstico.

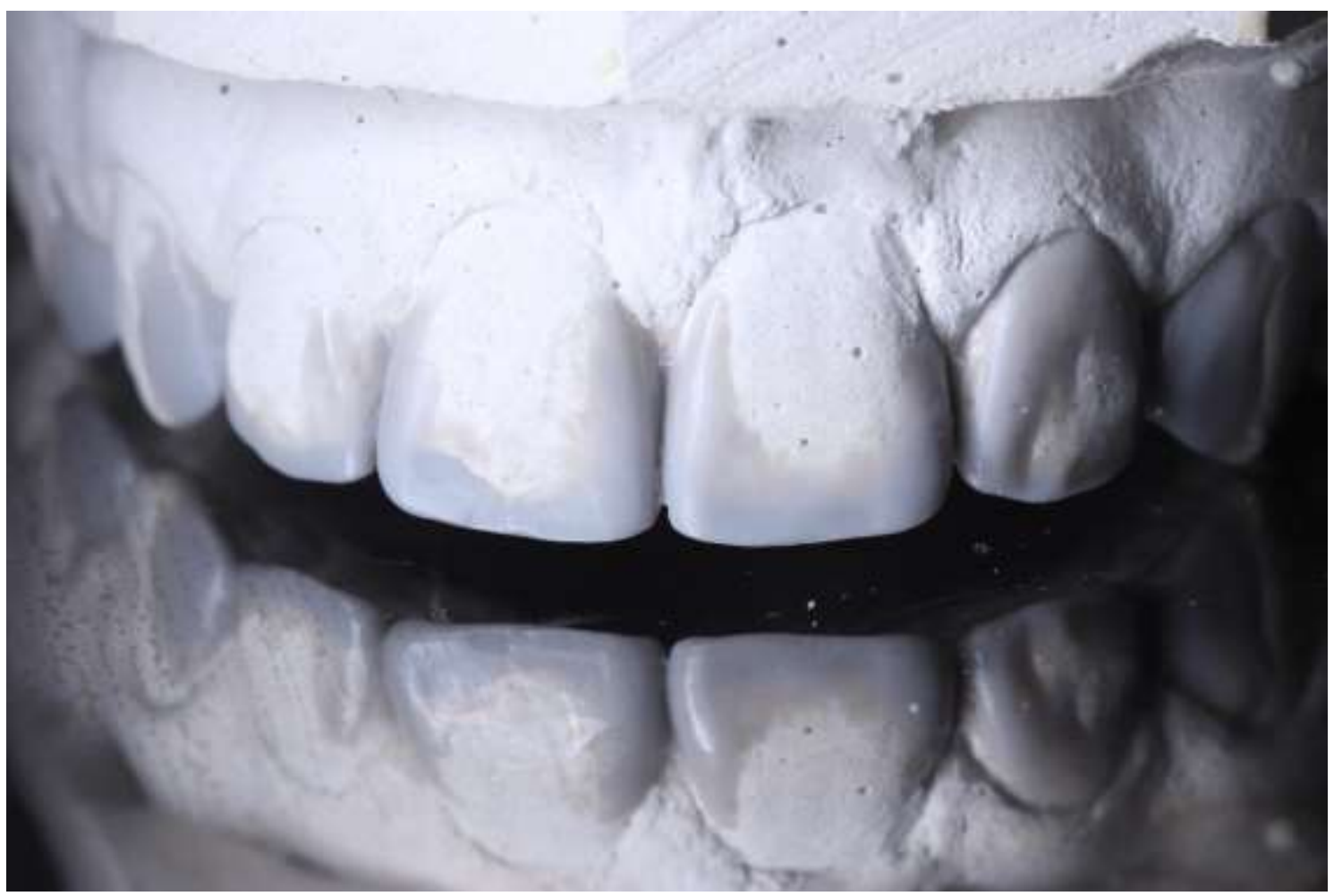

Fonte: Autores.

Na consulta seguinte, a guia palatina foi confeccionada, por meio da moldagem do enceramento diagnóstico, com o silicone por condensação (ExpressXT, 3M-ESPE, EUA) (Figura 6). A guia palatina permite ao profissional trabalhar com maior previsibilidade de resultados e segurança, possibilitando a estratificação de cores e minimizando os excessos de material.

Figura 6. Guia Palatina.

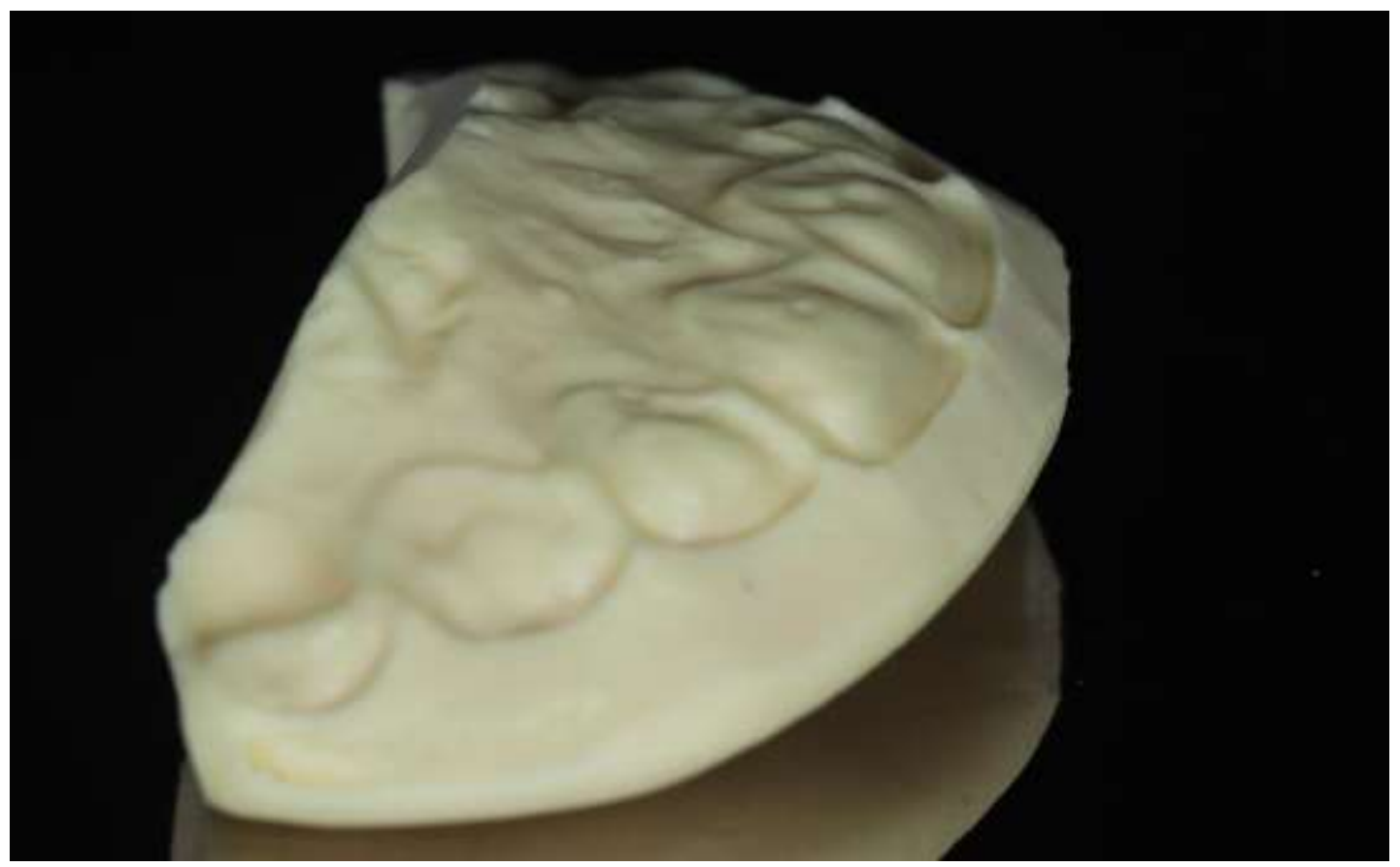

Fonte: Autores. 
Após esse momento, foi realizado o isolamento absoluto modificado, o qual não permite o contato do dique de borracha com o material restaurador, facilitando a inserção e o acabamento do material principalmente nas ameias gengivais. Feita a prova da guia palatina, foi realizado o condicionamento com ácido fosfórico a 37\% (Condac 37, FGM, Brasil) por 30 segundos e lavado em seguida (Figura 7). Adotou-se o sistema adesivo Single Bond Universal (3M-ESPE, EUA), de acordo com as instruções do fabricante, e o fotoativado por 20 segundos, utilizando luz halógena polimerizadora com intensidade de $1400 \mathrm{~mW} / \mathrm{cm}^{2}$ (RadiiLEDCuringLight, SDI, Austrália).

Figura 7. Condicionamento Ácido.

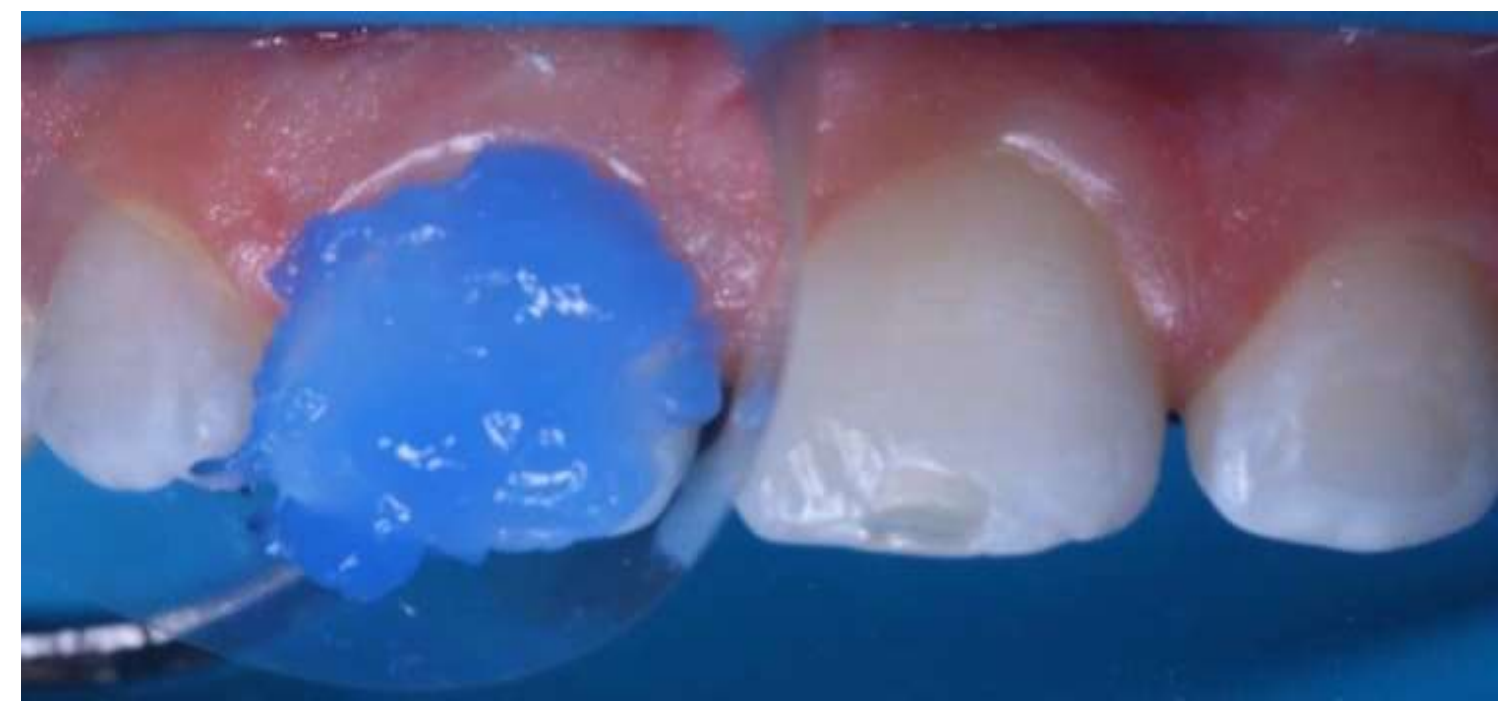

Fonte: Autores.

Foi acomodado, na guia de silicone, um incremento de resina composta de esmalte translucido Trans20 (Resina IPS, Empress Direct, Ivoclar Vivadent, Schaan, Lietchtenstein) nos dentes 13 ao 23 e, posteriormente, levou-se a guia fotoativada por 20 segundos (Figura 8) à boca da paciente. Dessa forma, obteve-se a face palatina com o formato e a forma préestabelecido pelo enceramento diagnóstico (Figura 9). Uma camada de resina de dentina DA1 (Resina IPS, Empress Direct, Ivoclar Vivadent, Schaan, Lietchtenstein) foi colocada sobre os dentes com o objetivo de conseguir uma opacidade referente à dentina. 
Figura 8. Matriz palatina posicionada em boca.

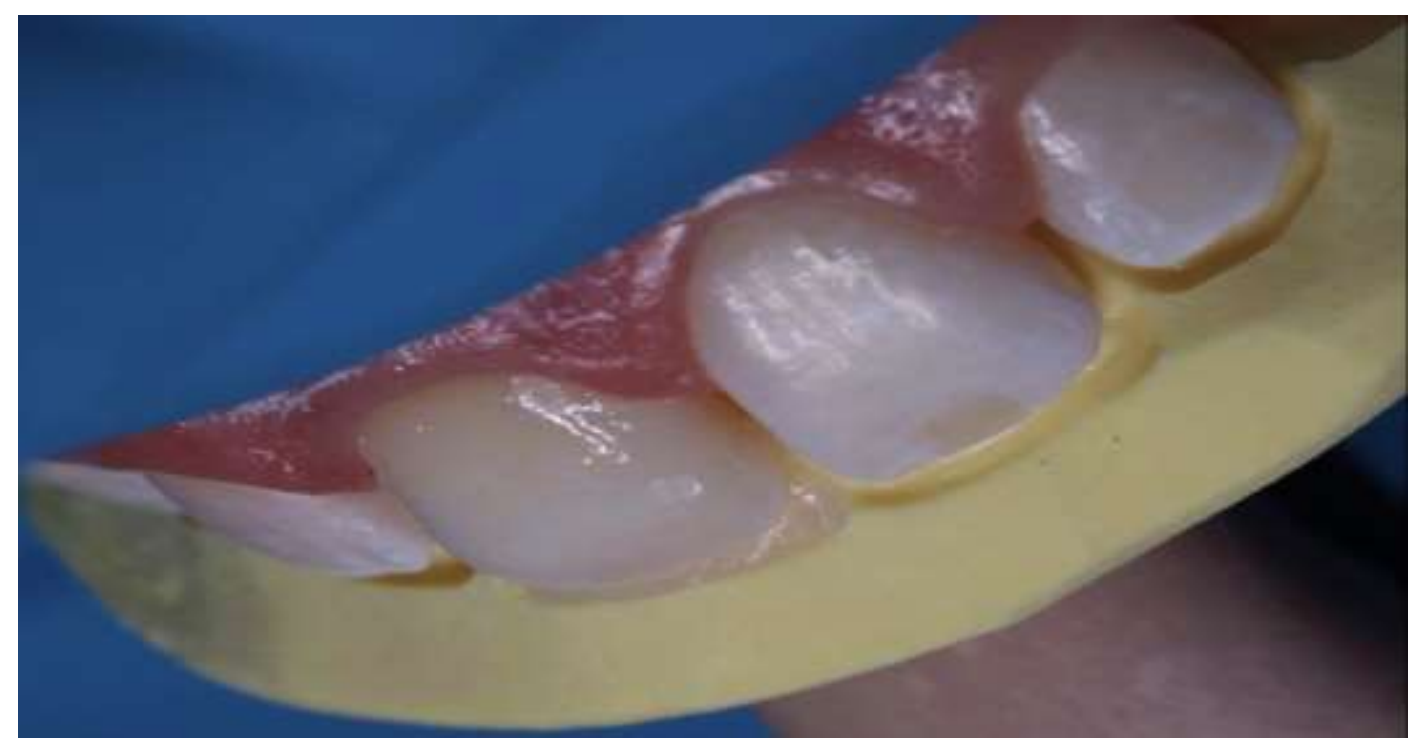

Fonte: Autores.

Figura 9. Confecção da concha palatina.

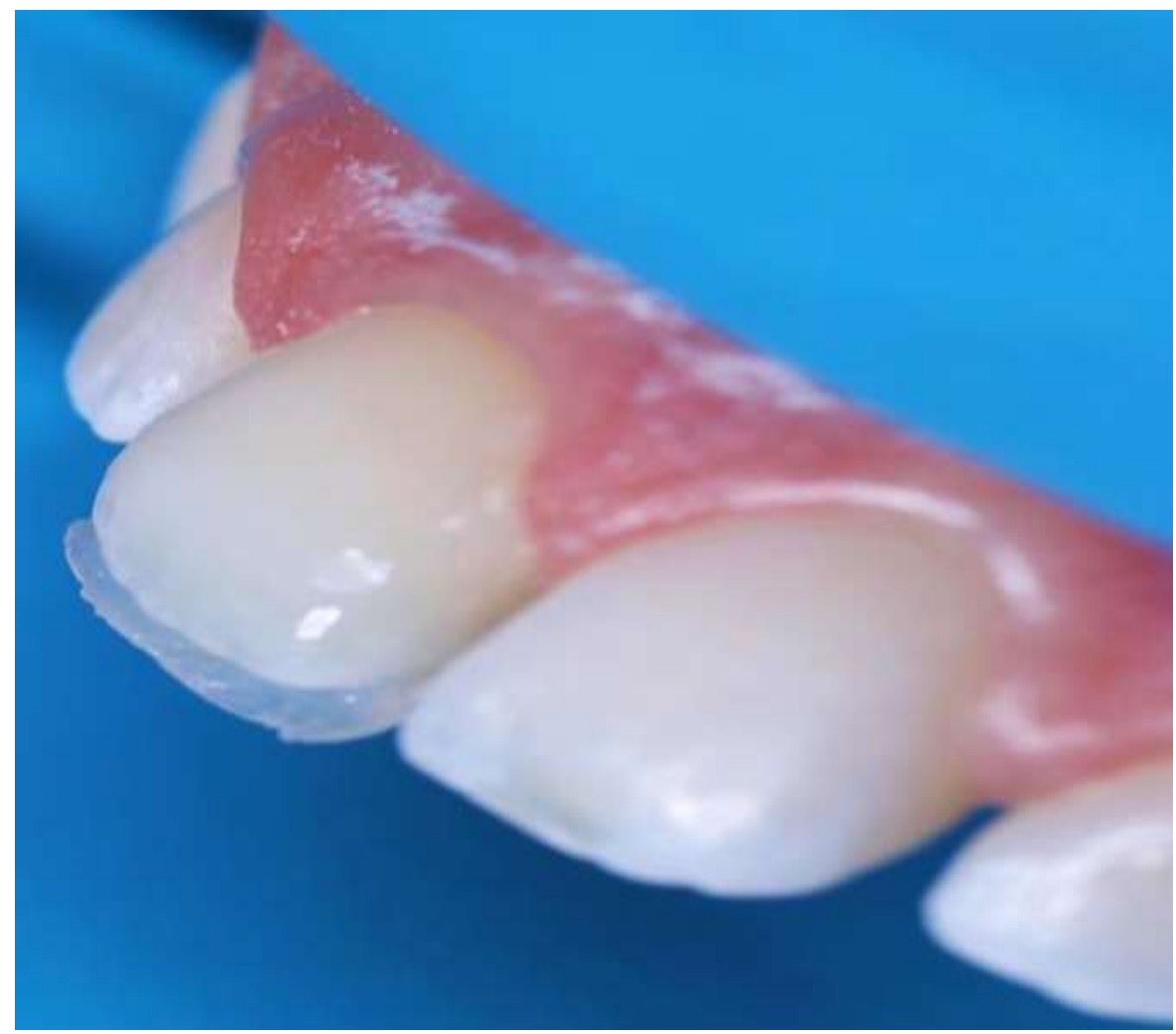

Fonte: Autores.

Por fim, o último incremento de resina de esmalte EB1 (Resina IPS, Empress Direct, Ivoclar Vivadent) foi colocado sobre a camada de dentina com auxílio de um pincel e, em seguida, esta foi fotoativada por 40 segundos. Ao término da restauração, os volumes dos incrementos foram verificados por vista incisal com auxílio de um espelho clínico e os contatos oclusais foram avaliados com o auxílio do papel carbono (Accu Film II, Parkell, EUA) e pontas diamantadas ultrafinas 2200FF e 3168 FF (KG Sorensen, Brasil) (Figura 10 e 11). 
Figura 10. Resultado final imediato.

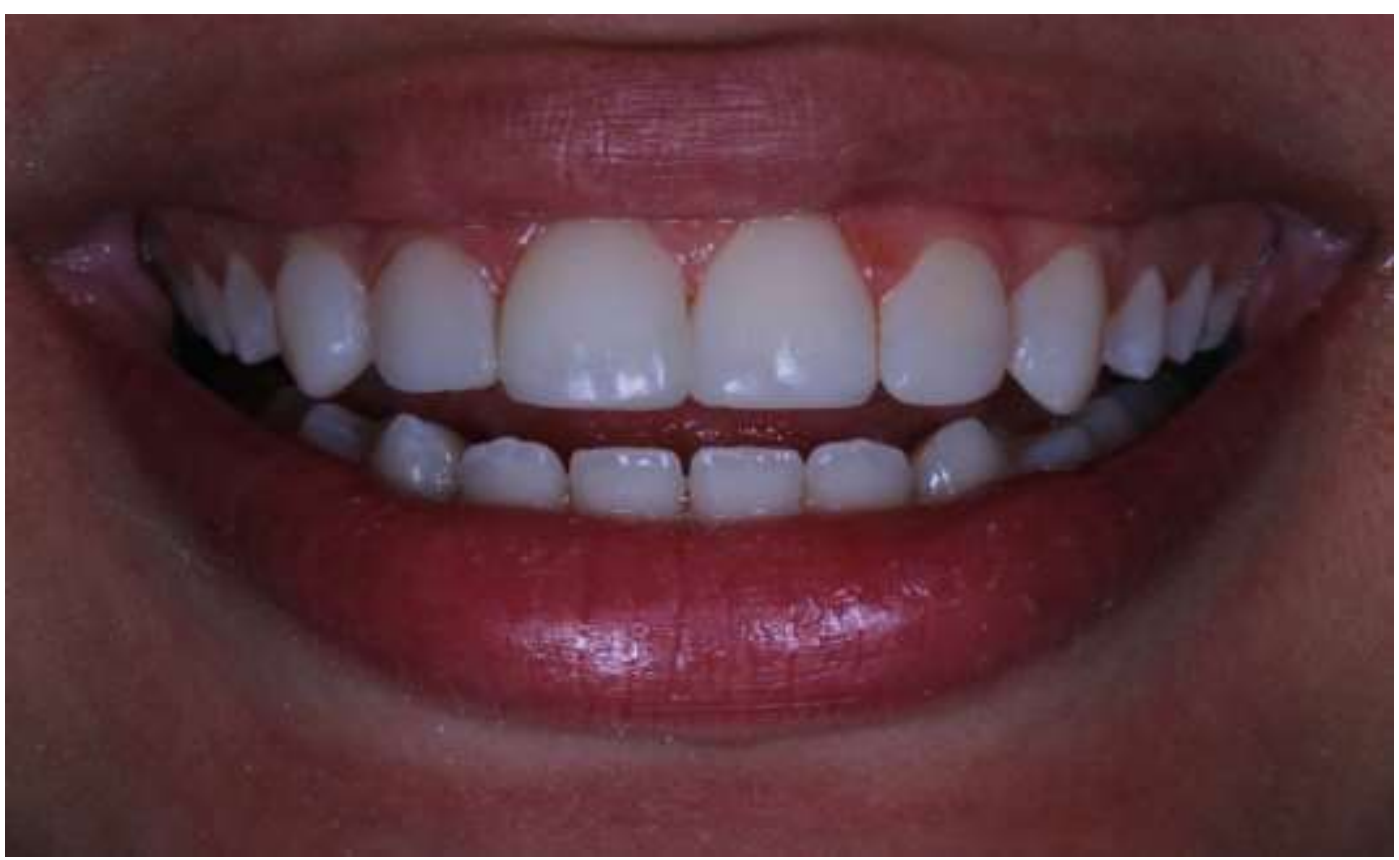

Fonte: Autores.

Figura 11. Resultado final imediato 2.

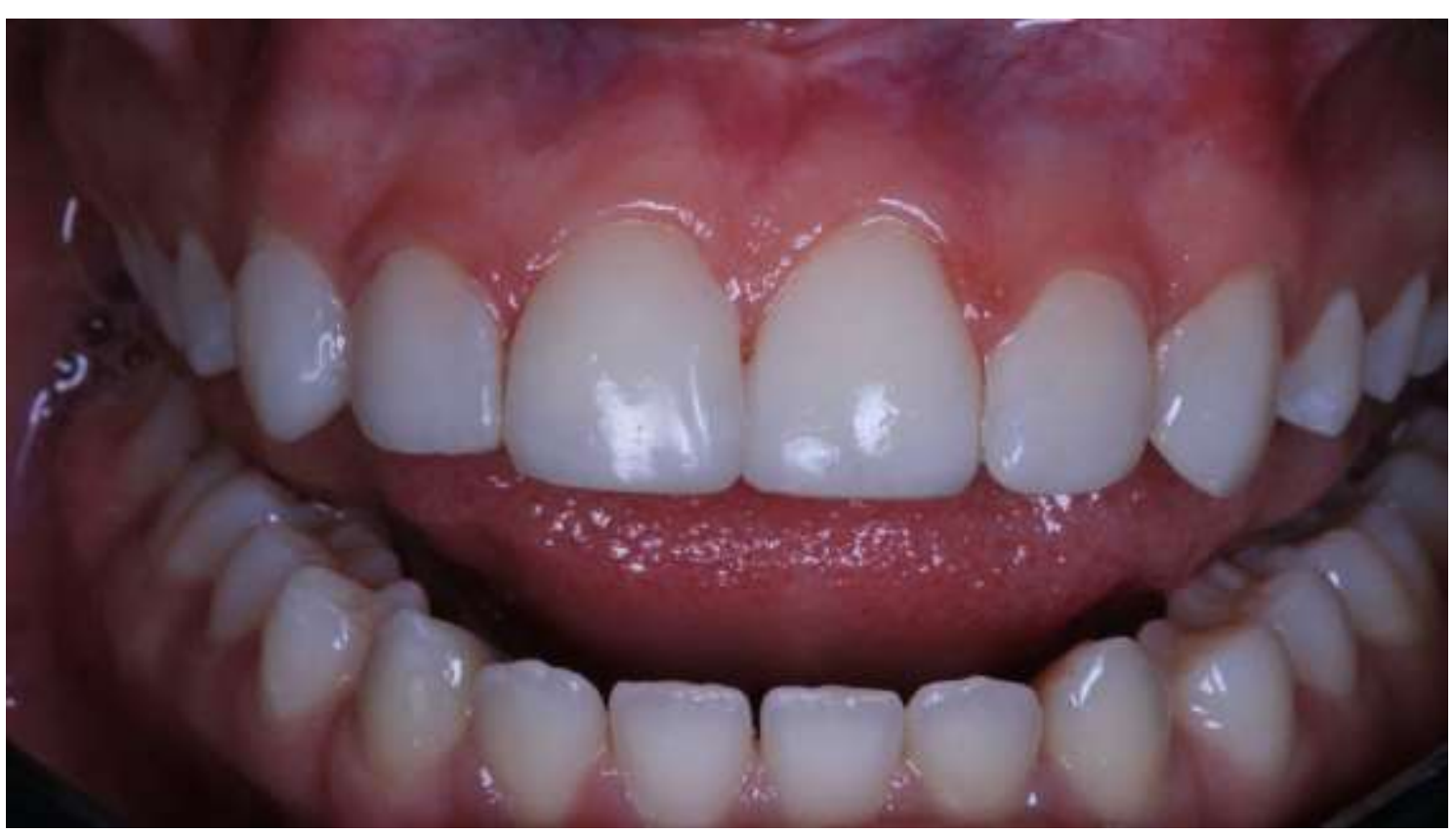

Fonte: Autores.

Em outra consulta, foram realizados os procedimentos de acabamento e polimento das restaurações. Para o acabamento, foi empregada a lâmina de bisturi número 12, além de pontas diamantadas ultrafinas $2200 \mathrm{FF}$ e 3168 FF (KG Sorensen, Brasil), polidores de granulometria grossa, média e fina em formato de taça (Ultra-Gloss, American Burrs, Brasil) (Figura 12), polidor diamantado espiral (JOTA, Suíça) (Figura 13) e discos de lixas de granulação fina (Sof-Lex, 3M-ESPE, EUA). 
Research, Society and Development, v. 10, n. 1, e7810111428, 2021

(CC BY 4.0) | ISSN 2525-3409 | DOI: http://dx.doi.org/10.33448/rsd-v10i1.11428

Figura 12. Polimento das restaurações com taça de borracha.

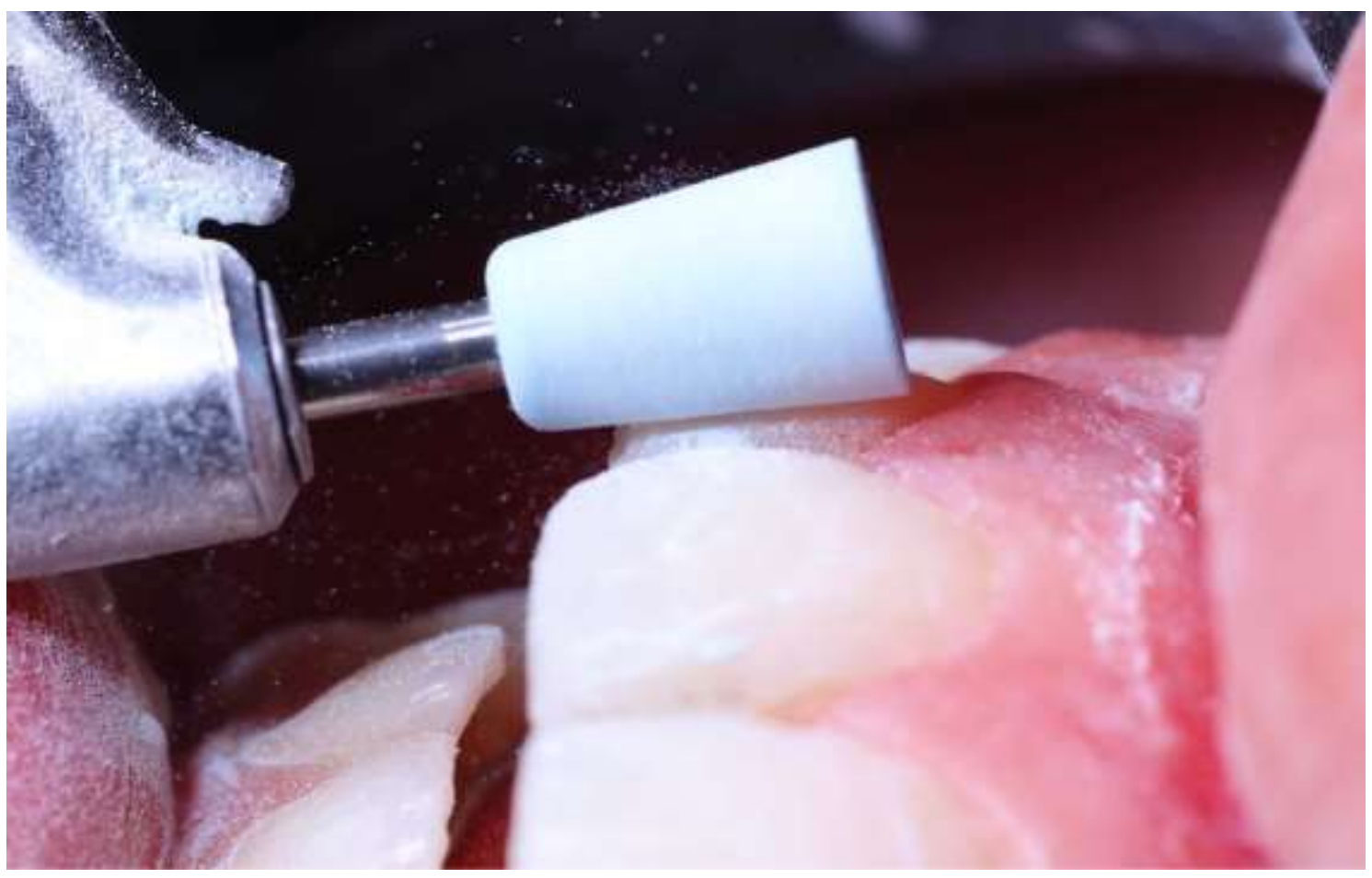

Fonte: Autores.

Figura 13. Polimento das restaurações com polidor diamantado espiral.

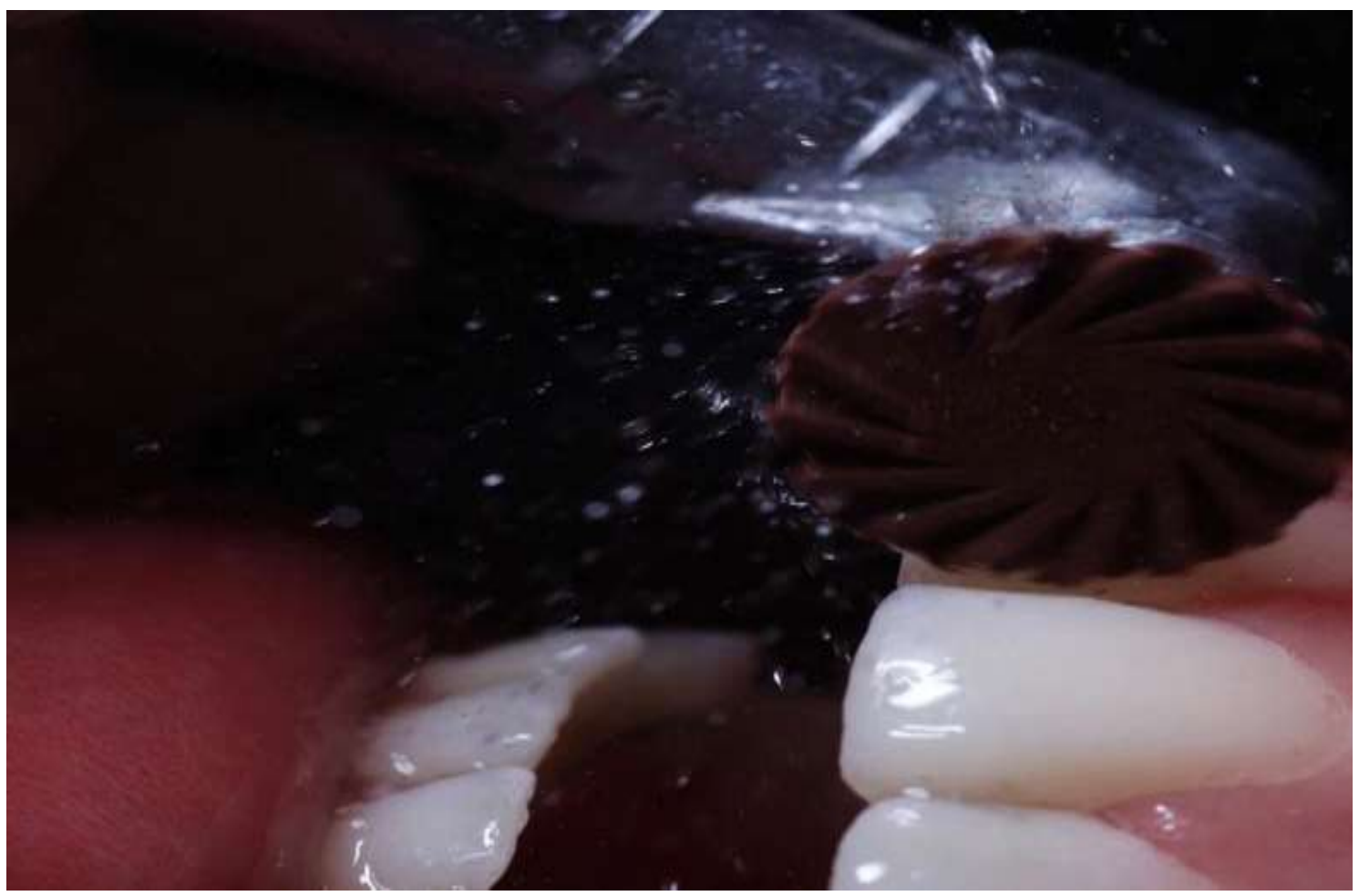

Fonte: Autores.

Cabe ressaltar que foram tomados os devidos cuidados com a margem gengival a fim de evitar excessos do material, visto que tais excessos podem favorecer o acúmulo de biofilme, provocando inflamação gengival. Finalmente, para o 
Research, Society and Development, v. 10, n. 1, e7810111428, 2021

(CC BY 4.0) | ISSN 2525-3409 | DOI: http://dx.doi.org/10.33448/rsd-v10i1.11428

polimento das restaurações, utilizou-se a pasta polidora Diamond Gloss (KG Sorensen, Brasil) com o auxílio de um disco de feltro (Feltros Diamond, FGM, Brasil), obtendo-se, então, o polimento final das restaurações (Figuras 14,15 e 16).

Figura 14. Resultado final após segunda sessão de acabamento e polimento: Vista lateral do sorriso.

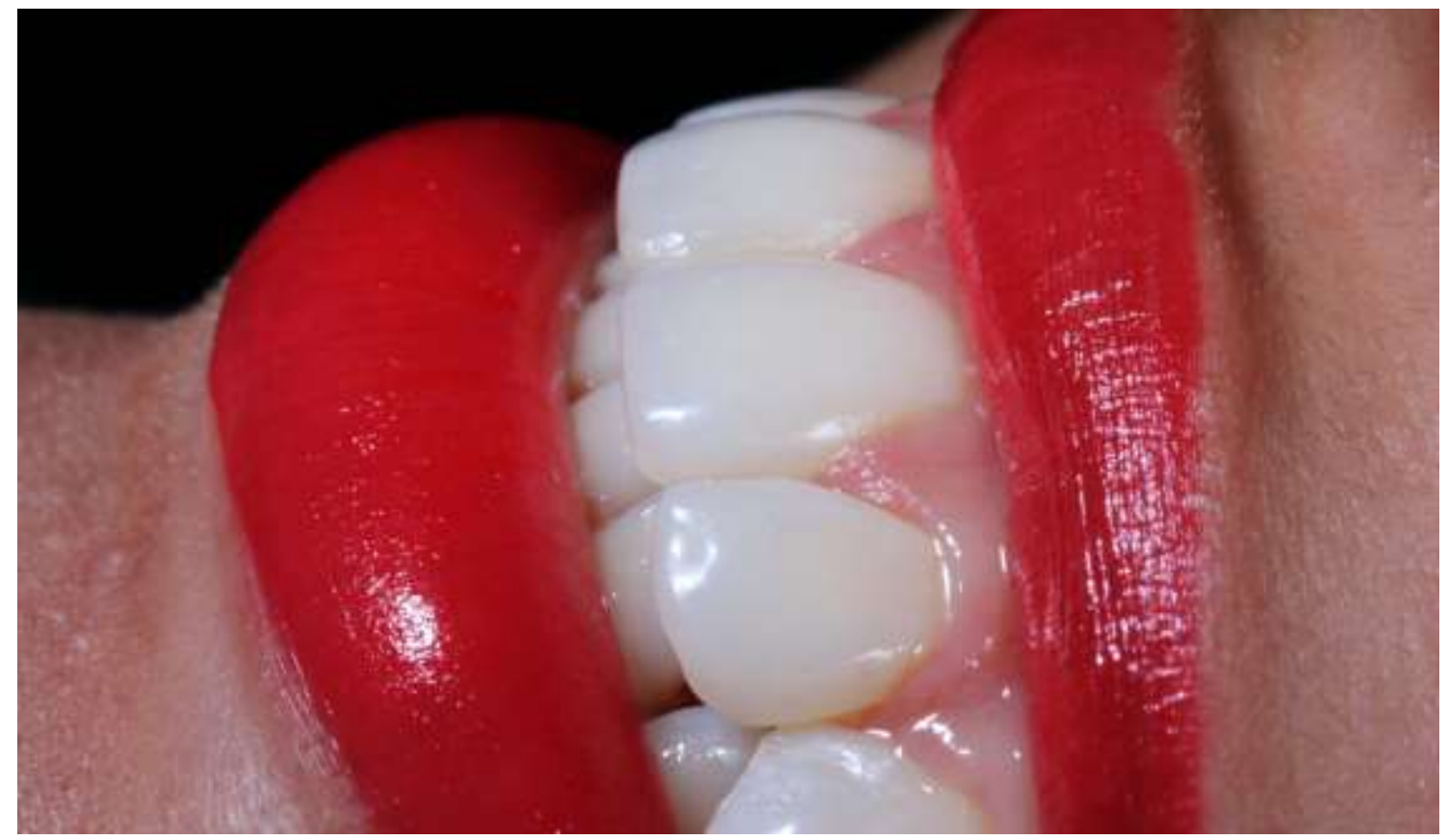

Fonte: Autores.

Figura 15. Resultado final após segunda sessão de acabamento e polimento: Vista frontal do sorriso.

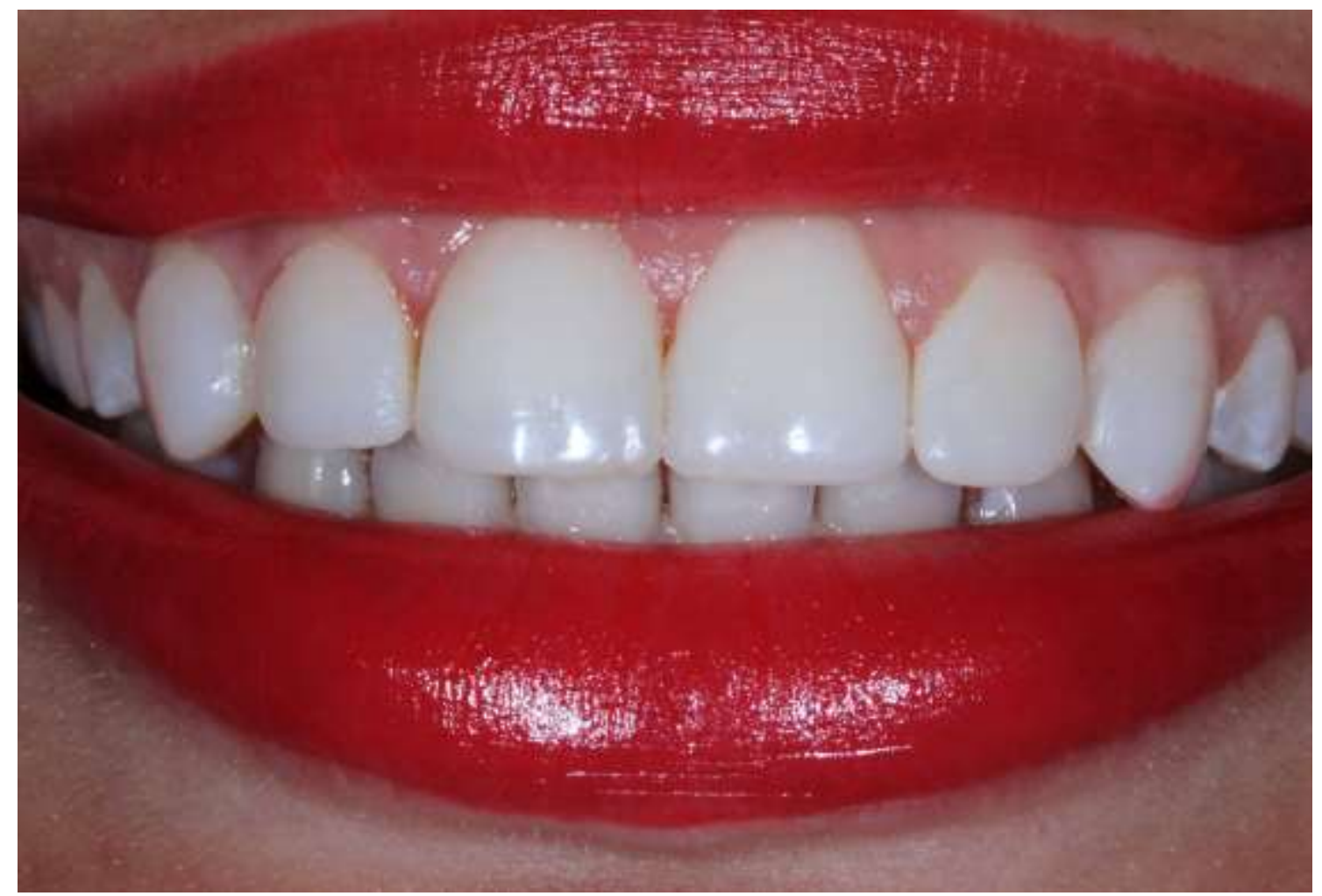

Fonte: Autores. 
Figura 16. Aspecto final do sorriso e satisfação da paciente após o término do tratamento.

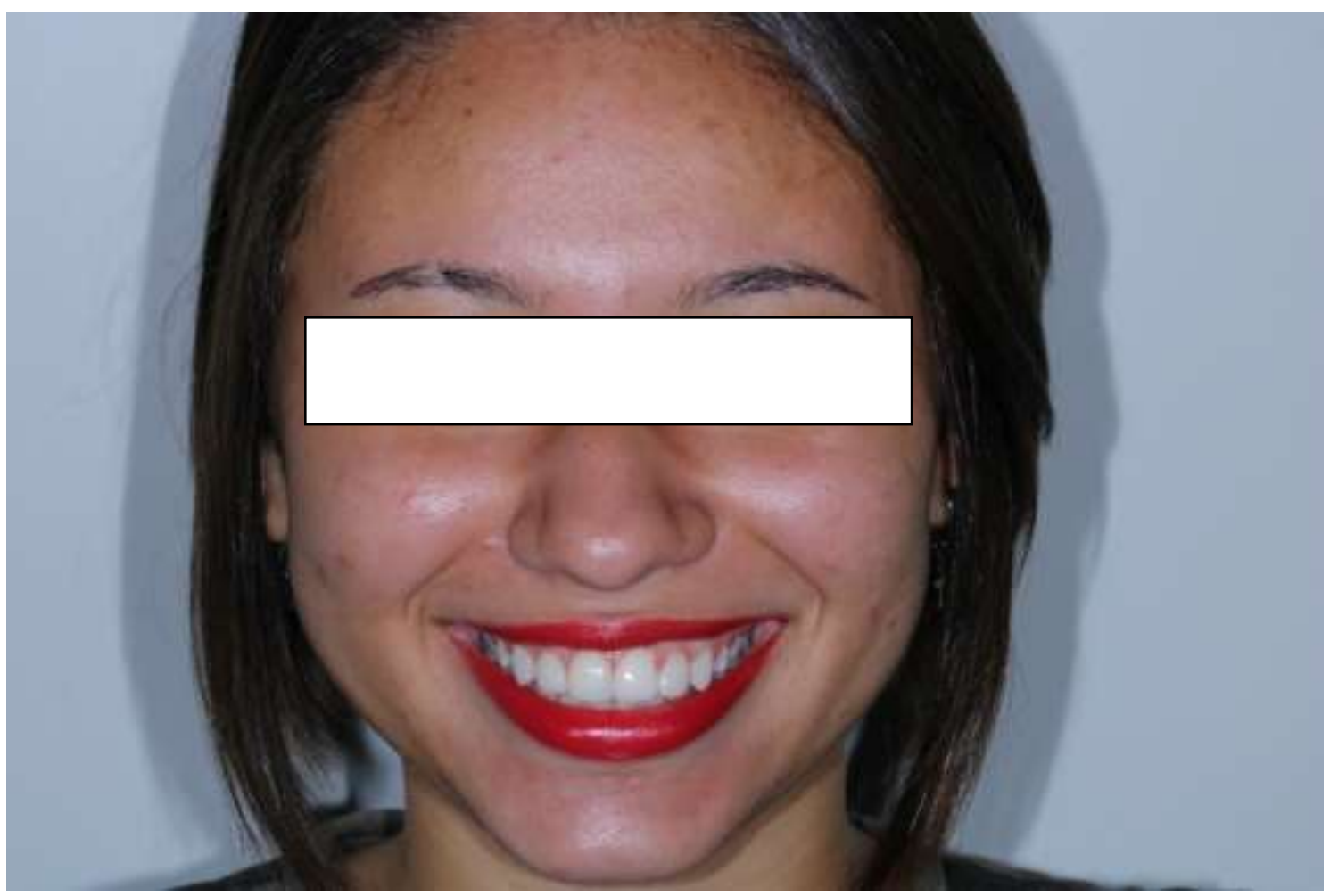

Fonte: Autores.

\section{Discussão}

Conforme já mencionado, a grande procura por procedimentos no campo da Odontologia Estética fez com que se elevasse rapidamente a demanda por técnicas restauradoras e materiais desenvolvidos para essa intenção. Tal fato, consequentemente, tem provido uma vasta gama de possibilidades para que se possa chegar ao sorriso "perfeito" (Paschoal, Santos-Pinto, Nagle \& Ricci, 2014; Bowen, Eichmiller \& Marjenhoff, 1996).

No entanto, é necessário que o profissional esteja sempre atento a fim de oferecer um tratamento livre de riscos ao seu paciente e que saiba lidar de forma adequada com problemas, como os diastemas. Esses podem ser definidos como um espaço entre os dentes ou a ausência de contato entre dois ou mais dentes consecutivos e podem ter origem patológica ou fisiológica ${ }^{16}$.

Tendo em vista o conceito de estética facial atualmente, ao se deparar com diastemas interincisivos centrais superiores, é necessário que o cirurgião-dentista manifeste pressa em tratá-los. Cabe, contudo, ressaltar que, antes de qualquer conduta, deve-se planejar a necessidade e o período mais oportuno para a execução de tal procedimento com base em evidencias sobre o desenvolvimento da oclusão e as etiologias das más oclusões que permitam distinguir o diastema fisiológico daquele que denota anormalidade e realmente requer tratamento (Kerosuo, Hausen \& Shaw, 1995; Freire \& Archegas, 2010).

Um dos possíveis tratamentos para esse problema é o uso de materiais restauradores indiretos, como as cerâmicas e porcelanas odontológicas, pois esses possuem estabilidade de cor, compatibilidade com tecidos periodontais, boa resistência mecânica e alto módulo de elasticidade. Em contrapartida, é preciso que seja realizado um número maior de procedimentos, além de haver um custo mais elevado e a necessidade de confecção de provisório. (Barreto, Gaglianone, Stape, Martins \& Soares, 2012; Azevedo, Galvão, Nihi, Hoeppner \& Nihi, 2015).

As resinas compostas, por sua vez, são consideradas excelentes materiais restauradores para inúmeras alterações estéticas. Isso porque possuem inúmeras cores, possibilidade de reparo e menor tempo de trabalho. Ademais, necessitam de pequeno ou nenhum desgaste da estrutura dentária e têm menor custo quando comparadas aos procedimentos indiretos, sendo, 
pois, o material dentário mais utilizado e pesquisado atualmente na odontologia (Demarco et al. 2015; Milnar e Wohlberg, 2013).

Em uma revisão de literatura realizada em 2015, constatou-se o bom desempenho clínico em dentes anteriores com restaurações em resina composta, com duração superior a três anos e baixo percentual de falhas. Salienta-se, entretanto, que o comportamento das restaurações é diferente em dentes anteriores e posteriores, uma vez que, nas regiões anteriores, apresenta menor incidência de cárie secundária e maior necessidade de troca por questões estéticas. Já em regiões posteriores, as trocas não são tão frequentes, mas há uma maior incidência de cáries por conta da dificuldade de higiene das restaurações (Bandéca, Calixto, Tonetto, Pinto \& Saad, 2011).

Nos casos em que a reanatomização dental é indicada, há inúmeras técnicas para o uso da resina composta. Uma delas é a estratificação com a guia de silicone obtida por meio do enceramento diagnóstico prévio. Essa técnica visa uma melhor adaptação da resina composta, maior facilidade de delimitação dos dentes e o posicionamento ideal do ponto de contato, além de mostrar uma prévia do resultado final. Uma outra alternativa é a técnica à mão livre, a qual, apesar de ter como vantagem o reduzido número de sessões clínicas se comparada ao uso da guia palatina, possui menor previsibilidade e depende muito da habilidade manual do cirurgião-dentista para a reprodução da excelência anatômica, função e estética do sorriso (Follak et al., 2012).

No que se refere ao acabamento e polimento, essas são etapas fundamentais para o sucesso clínico das restaurações estéticas diretas. Nesse sentido, a resina composta deve ser capaz de reproduzir fielmente a estrutura dental. Com o auxílio de discos abrasivos e pontas diamantadas com diferentes espessuras de granulações, é possível reproduzir depressões, projeções e suavizar a linha de transição entre restauração e dente a fim de se obter um resultado o mais natural possível e até mesmo tornar a restauração imperceptível (Baratieri \& Monteiro Jr., p. 806).

Por fim, destaca-se que, para apoiar uma tomada de decisão clínica e alcançar o sucesso do tratamento, fatores relacionados ao paciente, como higiene bucal deficiente ou presença de bruxismo, devem ser verificados. A investigação de tais fatores pode minimizar custos operacionais, além de aumentar a sobrevida dos procedimentos restauradores (Magne \& Magne, 2005; Gerard et al., 2019).

\section{Conclusão}

Diante do exposto, concluiu-se que as resinas compostas permitem a reabilitação estética do sorriso de forma direta com um bom custo-benefício e resultados excelentes sem desgastes teciduais, uma vez que sua retenção ocorre por meio dos sistemas adesivos e, quando bem empregadas, possuem uma longevidade satisfatória.

Ademais, constatou-se que a reanatomização dentária com o objetivo de finalização pós-ortodôntica pode ser necessária em casos que requerem mudanças em proporções dentárias, além de trazer uma maior satisfação estética ao paciente.

\section{Referências}

Almeida, R. R. [Renata], Garib, D. G., Henriques, J. F. C., Almeida, M. R. \& Almeida, R. R. [Renato]. (1999). Ortodontia preventiva e interceptora: mito ou realidade? R Dental Press Ortodon Ortop Facial, 4(6), 87-108. http://www.coraorto.com.br/arq_sys/neoeditor/file/mito\%20ou\%20realidade.pdf.

Azevedo, N., Galvão, G., Nihi, V. S. C., Hoeppner, M. G. \& Nihi, F. M. (2015). Otimização do Sorriso com Restaurações Diretas de Compósito Resinoso. Cient Ciênc Biol Saúde, 17(1), 43-9. https://revista.pgsskroton.com/index.php/JHealthSci/article/v iew/330.

Bandéca, M. C., Calixto, L. R., Tonetto, M. R., Pinto, S. C. S. \& Saad, J. R. C. (2011). Fechamento de diastema com resina composta. Clin, int. j. braz. Dent., 7(2), 156-164. Recuperado de http://revistas.ung.br/index.php/saude/article/view/784/950. 
Baratieri, L. N., Ritter, A. V. \& Andrada, M. A. C. (1994). Como melhorar o desempenho das restaurações estéticas diretas? In: Feller, C., Bottino, M. A. Atualização na clínica odontológica: a prática da clínica geral. São Paulo: Artes médicas.

Baratieri, L.N. e Monteiro Jr., S. (2010). Odontologia restauradora: fundamentos \& técnicas. Santos.

Barreto, B. C. F., Gaglianone, L. A., Stape, T. H. S., Martins, L. R. M. \& Soares, C. J. (2012). Restaurações de cerâmica reforçada por dissilicato de lítio: relato de caso clínico. Rev Dental Press Estét. 9(1), 86-94. https://issuu.com/rev-dentalpress/docs/estetica-v09n1-pt/44.

Bowen, R. L., Eichmiller, F. C. \& Marjenhoff, W. A. (1992). Gazing into the future of esthetic restorative materials. J Am Dent Assoc. 123(5), 32-9. https://scihub.wikicn.top/10.14219/jada.archive.1992.0137.

Demarco, F. F., Collares, K., Coelho-de-Souza, F. H., Correa, M. B., Cenci, M., Moraes, R.R, Nieck, J. M. O. (2015). Anterior composite restorations: a systematic review on long-term survival and reasons for failure. Dent Mater. 31(10), 1214-24. https://scihub.wikicn.top/10.1016/j.dental.2015.07.005.

Figueiredo, R. J. A., Andrade, A. K. M., Duarte, R. M., \& Medeiros e Silva, F. D. S. C. (2008). Otimizando a estética por meio de reanatomizações em dentes conóides. RGO.56(3),333-6.https://www.researchgate.net/publication/26585380_Otimizando_a_estetica_atraves_de_reanatomizacoes_em_dentes_conoides.

Follak, A. C., Ilha, B. D., Ribeiro, D. S., Mielke, J. C., Buligon, M. P., David, S. C. de \& Durand, L. B. (2012). Reanatomização e fechamento de triângulo negro em dentes ânterossuperiores. Revista Dentística on line, 11 (23), 26-32. http://coral.ufsm.br/dentisticaonline/1104.pdf

Freire, A. \& Archegas, L. R. P. (2010). Porcelain laminate veneer on a highly discoloured tooth: a case report. J Can Dent assoc., 76-126. https://www.researchgate.net/publication/47413968_Porcelain_Laminate_Veneer_on_a_Highly_Discoloured_Tooth_A_Case_Report.

Gerard, L. N., Cocco, A. R., Lund, R. G., Baldissera, R. A. \& Martos, J. (2019). Rehabilitation of anterior teeth with direct composite resin restorations: 3-year follow-up. J Clin Dent Res, 16(3), 10-21.

Gil, C. T. L. A. (2001). Proporção Áurea Craniofacial. Santos.

Gouveia, C. G., Moreira Junior, R., Peralta, F. S., Scherma, A. P. \& Resende, L. F. M. (2018). Facetas diretas de resina composta em dentes anteriores: relato de caso. ClipeOdonto. $\quad 9(1), \quad$ https://www.researchgate.net/profile/Felipe_Peralta2/publication/3312354 50_Facetas_diretas_de_resina_composta_em_dentes_anteriores_relato_de_caso_Direct_composite_veneers_on_anterior_teeth_a_case_report/links/5d4388bc4 585153e59353bc0/Facetas-diretas-de-resina-composta-em-dentes-anteriores-relato-de-caso-Direct-composite-veneers-on-anterior-teeth-a-case-report.pdf.

Higileh, Y. A. (2017). A estética do sorriso. [dissertação de mestrado]. Porto: Universidade Fernando Pessoa.

Kerosuo, H., Hausen, H., Laine, T. \& Shaw, W. C. (1995). The influence of incisal malocclusion on the social attractiveness of young adults in Finland. Eur J Orthod., 17, 505-512. https://scihub.wikicn.top/10.1093/ejo/17.6.505.

Magne, P. \& Magne, M. (2005). Treatment of extended anterior crown fractures using Type IIIa bonded porcelain restorations. J Calif Dent assoc., 33(5), 38796. https://jorgdentallabor.at/assets/docs/2006-05-magne-privdent02.pdf.

Milnar, F. J. \& Wohlberg, J. (2013). Direct resin veneers: case type V for AACD accreditation. Journal of Cosmetic Dentistry. 29(1), 110-118. https://stpaulsmiles.com/wp-content/uploads/sites/25/2016/03/Milnar-Wohlberg-Direct-Resin-Veneers.pdf.

Mondelli, J. (2018). Estética e cosmética em clínica integrada restauradora. (2a ed.). Santos.

Moraes, A. B. de, Webber, M. B. F., Marson, F. C., Progiante, P. S., Oliveira e Silva, Cleverson de \& Lolli, L. F. (2013). Reanatomização estética multidisciplinar em dente lateral conoide. Rev Dental Press Estét., out-dez; 10(4), 50-7. https://issuu.com/rev-dentalpress/docs/rdpe104-rgb-short/31.

Paschoal, M. A., Santos-Pinto. L., Nagle, M. \& Ricci, W. A. (2014). Esthetic and function improvement by direct composite resins and biomimetic concept. $J$ Contemp Dent Pract., 15(5), 654-8.https://www.researchgate.net/publication/272844161_Esthetic_and_Function_Improvement_by_ Direct_Composite_Resins_and_Biomimetic_Concept.

Rufenacht, C. (1998). Fundamentos de estética. Santos.

Sameni, A. (2013). Smile transformations with the use of direct composite restorations. Compend Contin Educ Dent., 34(5), 1-6. https://www.researchgate.net/publication/260379950_Smile_transformations_with_the_use_of_direct_composite_restorations. 
Research, Society and Development, v. 10, n. 1, e7810111428, 2021

(CC BY 4.0) | ISSN 2525-3409 | DOI: http://dx.doi.org/10.33448/rsd-v10i1.11428

Sene F., Kasuya A. V. B. (2016). Esthetic remodeling of maxillary incisors with composite resin: color, shape and proportion correction. J Clin Dent Res., 13(2), 70-7. https://clinicaldentistry.net/jcdr/jcdr-v13n02-2016-70/. 